\title{
Um Lugar para o Sujeito em Tempos de Consumo do Objeto: Um Estudo de Caso
}

\author{
Adriane Freitas Barroso ${ }^{1}$ \\ Pontifícia Universidade Católica de Minas Gerais
}

\begin{abstract}
RESUMO - A clínica psicanalítica sempre esteve conectada à realidade social, já que, a cada tempo, alteram-se as demandas e suas formas de endereçamento. Atualmente, contudo, o enfraquecimento do simbólico põe em xeque a crença no Outro, fazendo vacilar o lugar do sujeito e o conceito de clínica em si. Este artigo busca extrair, a partir de um caso clínico que aborda a questão da toxicomania, um esforço da psicanálise de orientação lacaniana para assegurar a importância do sujeito.
\end{abstract}

Palavras-chave: sujeito do inconsciente, clínica psicanalítica, real, simbólico, toxicomania

\section{A Place for the Subject in Times of Object's Consumption: A Clinical Case}

\begin{abstract}
Psychoanalytic clinic has always been connected to social reality, since each historical time brings different demands and singular ways to address them. However, nowadays, the weakening of the symbolic field calls the belief in the Other into question, and, therefore, the concepts of subject and clinic. This article aims to extract, from a clinical case that addresses the topic of drug consumption, an effort from Lacan's psychoanalytical orientation to ensure the role of the subject.
\end{abstract}

Keywords: subject, psychoanalytic clinic, real, symbolic, drug addiction

\section{Construção do caso clínico: particularidades metodológicas}

É verdade que, para ter a idéia do novo, é necessário conhecer o acumulado. Pesquisar é buscar, esperar o novo. [...] $\mathrm{Na}$ repetição temos segurança, mas, na vertente da pesquisa, não. Esta somente pode ser tratada, como nas "ciências duras", organizando lugares e produzindo encontros, lugares onde idéias e pessoas se cruzam e se manifestam ao acaso. Isto é tão importante como tudo aquilo que diz respeito ao sistemático. É a esta vertente que me dirijo deixando de lado todo o sistemático, o fundamental que sustenta toda a atividade, mas que somente interessa na medida em que dá lugar ao a-sistemático e ao singular (Miller, 2003, p. 20).

O trecho acima explicita o que, neste artigo, compreendemos ser um trabalho de pesquisa: um movimento em direção ao não saber, mais do que a repetição do saber já estabelecido. Da mesma forma, conjugando decifração e construção, o inconsciente é fundado, e daí a afirmação de Freud (1912/1996) de que deveríamos, como psicanalistas, escutar cada caso como se fosse o primeiro, sem crer demasiadamente no saber prévio.

Esse caráter de construção permanente e de inacabamento que marca a psicanálise imprime-se, como não podia deixar de ser, à escrita da clínica nesse campo. Cada caso clínico convoca, em certa medida, a uma leitura original: "é preciso darmo-nos conta de que a Psicanálise não é uma ciência, não é uma ciência exata". (Lacan, 1977, p. 14). Afinal, há sempre algo não generalizável nas manobras de um sujeito com seu sintoma.

1 Endereço para correspondência: Rua Juiz de Fora, 115/1206, Barro Preto, Belo Horizonte, MG, Brasil. CEP: 31.180-060. E-mail: adrianebr@gmail.com
Buscamos fazer dessas premissas o fio condutor para a composição do caso clínico que se segue neste artigo. Seu lugar não é o de ilustração da teoria, mas de substrato, terreno de onde brota a pesquisa teórica empreendida paralelamente à sua escrita, com o objetivo de clarear seus pontos nebulosos.

A questão que nos move neste percurso pode ser resumida da seguinte forma:como situar sujeito do inconsciente e a concepção de clínica no contexto atual, de enfraquecimento da instância simbólica? Como pode a psicanálise continuar a operar com o sujeito, que tem a linguagem e o desejo como pressupostos, diante da descrença no Outro e dos modos de vida centrados na relação solitária com o objeto, como vemos, por exemplo, na toxicomania?

A psicanálise não é o efeito de um saber do Outro sobre uma história e, sim, ofeliz encontro entre as ferramentas conceituais do analista - pulsão e objeto, por exemplo - e as contingências de uma história, produzindo um caso e, no melhor dos casos, um novo sujeito. Buscamos, assim, estar próximos da possibilidade de constituir enunciados positivos sobre este saber propriamente psicanalítico, singular e inventado a cada nova situação (Figueiredo, 2004, p. 81).

\section{Lucas: crer no pai, não crer na droga}

Quando chega ao consultório pela primeira vez, aos 15 anos de idade, Lucas havia sido flagrado pela polícia com uma pequena quantidade de maconha. Estaria sujeito a alguma das medidas socioeducativas previstas na Lei 8.069 (1990), que dispõe sobre o Estatuto da Criança e do Adolescente para autores de ato infracional, mas o juiz responsável por seu caso havia decidido dar a ele "uma chance" (entre aspas, nesta seção, apresentamos falas trazidas pelo sujeito e intervenções da analista): não cumpriria medida formalmente, desde que 
fizesse um acompanhamento psicológico. É sua mãe que liga para a analista para agendar o atendimento do filho.

Lucas chega ao consultório com um ar apático e declara não ter nada a dizer. Afirma estar ali cumprindo ordens, mas não as do juiz: "vim só porque minha mãe mandou". Não se implica no episódio que gerou o flagrante da polícia, afirmando não ser "traficante" nem "viciado". Seu tom monocórdico altera-se apenas quando conta que sua mãe teve que buscá-lo na delegacia após sua apreensão: "tive pena de ver ela ali, tendo que me tirar daquela situação". A analista afirma que, então, sobre a mãe, ele tinha algo a dizer, e encerra a sessão.

Lucas retorna uma semana depois, consentindo em contar mais sobre o episódio em questão: "eu estava fumando com os meninos da minha rua. A polícia sempre passa, mas não mexe com a gente. Dessa vez, eu rodei". Os demais conseguiram fugir. Ele assume que é quem vende a droga para esses "chegados", mas não entende a atividade como tráfico: "vou comprar pra mim, aí compro a mais pra eles e ponho o meu [lucro] no valor que repasso. De boa, sem neuras".

Lucas explica que usa a droga para se "desligar": sem ela, sente-se "impulsivo", envolvendo-se em brigas e agressões na rua, quase todas relacionadas a mulheres. Não por acaso, o grupo com quem fuma é formado exclusivamente por homens: "mulher enlouquece muito a gente". Não acredita que a droga o atrapalhe, embora seu desempenho na escola seja pífio e não tenha planos de trabalhar ou estudar. Também diz ter certeza de que maconha não vicia: "é uma diversão, sem consequências". A analista pontua: "mas você rodou. Para você, dessa vez, houve consequências".

Lucas não tem amigos fora do círculo de uso da maconha e nutre uma relação difícil com os familiares. Vem de uma família de classe média, em que a mãe, ele diz, "se mata para não deixar faltar nada". Seu amor por ela é "sem limite", "mas ela me irrita muito, fala muito na minha cabeça, me cobra. Não sou como ela queria que eu fosse". O pai, por sua vez, sempre viveu de trabalhos temporários, em uma situação precária tanto do ponto de vista financeiro quanto de saúde. O divórcio dos pais veio por conta de sucessivos episódios de agressividade do pai, gerados pelo uso "exagerado" de álcool, que culminou também em sua morte por cirrose poucos anos depois, quando Lucas tinha 13 anos. Lucas diz que o pai lhe ensinou muitas coisas, apesar de ser "sem limite, de não saber se controlar", e encerra dizendo: "do meu pai, não tenho mais nada pra falar". A sessão é cortada e a analista afirma que o esperaria para que continuassem a falar sobre o nada do pai.

Após três meses de exposição desses rudimentos de seu romance familiar, Lucas interrompe sua análise sem aviso prévio. As tentativas de contato que se sucederam mostraram-se infrutíferas. A analista decide que não seria $o$ caso de ligar para a mãe demandando o retorno de seu filho, mas avisa a ela sobre sua ausência e faz um relatório sucinto e com informações objetivas para ser entregue à instância jurídica. Cerca de um mês depois, a mãe envia à analista uma mensagem de celular agradecendo e dizendo que o juiz havia consentido em encerrar o caso de Lucas.
Foi com muita surpresa, portanto, que a analista recebeu, cinco anos depois, nova ligação dessa mãe solicitando uma sessão para o filho. A repetição dessa cena - a mãe ligando para marcar um atendimento para Lucas, mesmo este tendo, agora, 20 anos - fez supor que se trataria de um novo episódio relativo ao uso de drogas ou a algum embaraço com a lei. Não é sobre isso, contudo, que ele vem falar dessa vez: " as coisas mudaram. Minha mãe perguntou se eu queria a ajuda de um profissional e eu aceitei, porque está muito difícil. Estava namorando, feliz demais, e ela de repente terminou comigo. Não estou conseguindo levar sozinho, é muita dor".

O relacionamento em questão havia começado um ano antes, após o então namorado da menina ser preso por porte de drogas. Quando esse "ex" é solto, ela termina o namoro com Lucas dizendo-se confusa: "a gente estava bem, ela falava que me amava. Como isso pode mudar assim?". A analista encerra a sessão afirmando: "é, as coisas mudaram".

Nos dias que se sucedem, a ex-namorada consente em manter alguma proximidade, mas continua dizendo que não quer reatar o namoro com Lucas: "ela me enlouquece. Da última vez que nos vimos, bebi demais, fiquei louco e xinguei muito, ela foi embora com ódio. Fiquei sem limite. Eu tento não telefonar, mas é mais forte do que eu".

Todos os términos de namoro de Lucas foram semelhantes quanto aos efeitos que causaram: "eu fico muito bem namorando, fico calmo, focado, e quando o namoro termina parece que eu perco tudo". A iniciativa do término é sempre das mulheres, e ele se diz invariavelmente pego de surpresa: "eu sou bobo. Com as mulheres, sempre rodo". A analista relembra-o que ele também "rodou" quando vendia drogas. "Sou um bobo que acha que é esperto, ou o esperto mais bobo", ele diz.

Esclarece que, há alguns anos, desistiu de vender drogas. Depois de um tempo nessa atividade, havia conseguido economizar quatro mil reais - quantia elevada para o padrão de vida que sua mãe podia proporcionar - e resolveu gastar todo o dinheiro de uma vez só, em uma viagem de férias. Quando retornou a Belo Horizonte, decidiu que começaria a trabalhar. Por conta da "boa aparência", conseguiu emprego como "vendedor de uma loja de roupas caras" em um shopping center da zona sul. Seu salário, contudo, nem se compara ao dinheiro que a droga lhe rendia. Lucas vacila ao falar sobre o tema: "é muito sacrificio pra ganhar muito pouco. As vezes penso que vender maconha poderia ser uma saída de novo, só por um tempo, até tudo se ajeitar e eu ficar melhor". Da analista, escuta mais uma vez: "as coisas mudaram". A sessão é encerrada.

$\mathrm{Na}$ semana seguinte, Lucas conta que, pouco antes do término do namoro, havia começado a fazer cursinho para tentar passar no vestibular. Decidiu retomar os estudos pelo mesmo motivo que não o deixava, até aquele momento, voltar a vender drogas: "antes de morrer, meu pai disse que me daria três conselhos: estudar, estudar e estudar". Relembra que foi quem cuidou do pai no hospital antes de seu falecimento e que, apesar de seu péssimo estado de saúde, recebeu a notícia de sua morte com susto e revolta: "quando fui avisado, não sei explicar, nem lembro muito porque saí do ar, mas fiquei 
com muita raiva. Ele não teve limite". A sessão é encerrada após a analista repetir, enfática: "ele não teve limite".

Lucas chora dizendo que tem tentado "fazer tudo certo" - o que, para ele, é sinônimo de estudar e trabalhar -, mas que, após o término do namoro, não consegue levar as coisas adiante: "fiquei sem chão". Pensa em sair do cursinho, decide mudar de emprego e vai trabalhar em outra loja do mesmo shopping center, mas continua aventando a possibilidade de voltar a vender drogas "por um tempo".

Enquanto a dor do término parecia insuportável, Lucas manteve-se indo regularmente às sessões, marcando várias outras sessões extras, ligando quando estava angustiado para "ficar calmo" ouvindo a voz da analista. Dois meses depois de seu retorno, contudo, anuncia que a vida está "voltando para o lugar", que consegue pensar com mais clareza... e não retorna ao consultório, deixando para trás uma sessão não paga e as demais tentativas de contato da analista, como cinco anos antes, sem nenhuma resposta.

\section{A realidade social em que vive Lucas e a toxicomania como seu paradigma}

"O saber do mestre se produz como um saber inteiramente autônomo do saber mítico, e isto é o que se chama de ciência" (Lacan, 1969-1970/1992, p. 84).

Foi o discurso científico que tornou possível pensar o sujeito cartesiano como agente, dedução do pensamento, não mais apenas a partir de uma ontologia ou de uma metafísica, como fruto da natureza ou da vontade divina. Esse sujeito do discurso científico, contudo, visa a um "homem sem qualidades", determinado apenas pela razão. Coube à psicanálise, a partir no século XX, sublinhar o desejo como o que impede qualquer assepsia pretendida pela ciência: "o sujeito do inconsciente é o que subexiste recalcado sob o sujeito da ciência" (Lopes, 2009, p. 19). Há o inconsciente, há a pulsão e, por consequência, não há o sujeito universal.

Esse panorama da civilização ocidentalizada que viu nascer a psicanálise foi profundamente modificado após a II Guerra Mundial. Sendo o inconsciente um efeito da linguagem, o sujeito respondeu a essa alteração na cultura, apresentando-se com outra roupagem. Lacan (1970/2003) pôde, no último momento de seu ensino, antecipar as consequências dessa mudança na clínica psicanalítica, no fenômeno que ele chamou de ascensão do objeto a.

A realidade social que surge a partir daí estabelece a produção e a troca generalizada de produtos de consumo, em uma pluralização de objetos fabricados pela associação entre ciência e mercado, destituídos de valor em si e reduzidos à sua vertente utilitária. Os modos de gozo atendidos por esse mercado podem ser resumidos pela expressão publicitária "enjoy x", que a multinacional Coca-Cola tornou mundialmente conhecida: o triunfo do enjoyment, do gozo, sobre a satisfação adiada do recalque, que era a marca registrada da clínica freudiana (Brousse, 2007).

Ironicamente, diz Blanco (2007), o que se esconde por trás da ideia de mercado global é um empuxo individualista. Sem o amparo de discursos preestabelecidos, a multiplicação dos objetos determina o recrudescimento do Outro como função limitadora. Se o supereu freudiano produzia a proibição, o dever, a culpabilidade, termos que supunham esse Outro, o último ensino de Lacan entrevê a pulverização dos significantes-mestres, incluindo-se aí o Nome-do-Pai, que, como todos os outros S1, revela sua condição de semblante e seu caráter arbitrário, sendo, por isso, posto em questão. Essa derrocada elide a condição do sujeito dividido, que é a orientação pelo desejo, e o supereu de que fala Lacan (1972-1973/1995) passa a ser o que vocifera “goza!": "aí eu aponto a reserva que implica o campo do direito-ao-gozo. $\mathrm{O}$ direito não é o dever. Nada força ninguém a gozar, senão o superego. O superego é o imperativo do gozo - goza!" (Lacan, 1972-1973/1995, p. 11).

É essa a realidade a que responde a clínica psicanalítica hoje, e é de seus modos de vida que Lucas é testemunha. Em lugar dos embaraços trazidos pela linguagem, em lugar do sofrimento e do enigma oriundos do recalque, em lugar da angústia diante da impossibilidade de relação sexual entre os seres falantes, Lucas escolhe, inicialmente, a conexão imediata com o objeto da pulsão. Não haveria, de sua parte, qualquer demanda prévia de análise, uma vez que a palavra encontrava-se em estado de inoperância. Sem a obrigatoriedade imposta pela lei jurídica, podemos supor que ele nunca chegasse a se colocar diante de um analista. Aliás, ainda que tenha cumprido a determinação do juiz responsável por seu caso, cabe ressaltar sua falta de implicação e sua dessuposição de saber também em relação a essa instância. O Outro a quem Lucas respondia não é o simbólico: "só vim porque minha mãe mandou”, ele afirmava, a princípio.

Afirmamos que o gozo solitário com a droga é a tentativa desse sujeito de regular os excessos do Outro em sua vertente imaginária. Nessa proximidade com o objeto, eleito como parceiro (Portillo, 2005), pode-se tamponar, artificial e momentaneamente, os efeitos do recalque e não se perguntar sobre o sintoma. A droga é, pois, exemplar na substituição que faz imperar o Um do real de gozo sobre o Outro simbólico das regulações próprias ao laço social.

Haveria uma explicação universal para o lugar privilegiado da droga em nossa realidade? A psicanálise acredita que não, pois o uso que se faz dela é sempre uma resposta singular. Por outro lado, torna-se fundamental debater o discurso em que esse modo de gozo se faz tão presente, tornando-se uma saída comum para o mal-estar de hoje. Utilizando a expressão "nosso modo de gozo", Lacan (1974/2003, p. 523) indicou que há, afinal, uma abordagem do gozo que passa pelo coletivo, para além de sua vertente singular. Todo sintoma seria também social e tocaria, em um de seus vértices, o universal da estrutura:

Sintoma social situaria assim um campo do particular, entre o universal do mal-estar e o singular do sintoma subjetivo: metáfora partilhada por um grupo do mal-estar, por meio de uma modalidade de gozo inscrita, submetida e provocada pelo discurso dominante de uma época (Vorcaro, 2004, s.p.).

A droga como fenômeno de incidência global responde à mudança de regime do mestre antigo para o moderno, capitalista, o que definiu alterações na relação do sujeito com o saber. Ela é mais um objeto que tem sua circulação 
condicionada ao imperativo de consumo, explicitando de forma paradigmática a ligação entre o ser falante e a realidade marcada pela suplantação do gozo fálico por um gozo que busca prescindir do pacto social e se apresentar como pleno.

A clínica psicanalítica, como era de se esperar, espelha essa mudança. Leite (2001) explica que os sintomas de hoje (toxicomanias, transtornos alimentares, hiperatividade, depressão, para citar apenas alguns dos mais comuns) expressam o mal-estar de termos nos tornado consumidores e, ao mesmo tempo, objetos de consumo, no que poderíamos chamar de uma toxicomania generalizada. Tem-se aí a prevalência de uma forma de uso, tanto dos produtos do mercado quanto do outro como semelhante, que é desprendida do Outro, promovendo um gozo repetitivo, fechado em si e limitado ao circuito consumidor-produto (Santiago, 2001). Refratárias à dimensão do sentido, as patologias contemporâneas desvelam a presença de um real sem lei, excluído do saber do inconsciente. Cai o significante-mestre que comandava a civilização sob a lógica do semblante e proliferam-se as diversas emergências do real, na busca incessante por satisfação. Entre essas manifestações, o objeto-droga ganha destaque.

No campo da psicanálise, entendemos que o enganchamento entre sujeito e objeto a que assistimos no paradigma da toxicomania pode promover um by-pass, um recurso que elide a significação. A queda do efeito de sentido suspende temporariamente os efeitos da castração e produz, por acréscimo, um excedente de satisfação, elidindo as questões do sujeito a respeito dos embaraços com o corpo e com o Outro sexo. Trata-se de um substituto do sintoma neurótico e da falta-a-ser, uma ruptura com o gozo parcimonioso que é decorrente da parceria fálica. Estamos dizendo, portanto, de um recurso cínico, que se propõe a eliminar a angústia do encontro com a falta.

O cínico moderno, ao contrário do sábio cínico, não tenta fazer uma lei ética de seu modo de gozo. Ele satisfaz-se com sua própria maneira de gozar - à margem, no seu canto, não tem a menor intenção de demonstração. É assim que se pode explicar sua péssima reputação com os representantes das leis da cidade. Ele representa, além do mais, uma perturbação para essas leis, um obstáculo maior ao discurso do mestre, colocando-se fora do alcance dos esforços da retórica para inseri-lo nas vidas dos ideais da sublimação (Santiago, 2001, p. 159).

\section{Conclusão: que outra saída é possível para o sujeito?}

Lucas é um toxicômano? As respostas a respeito dos aspectos que permitiriam essa nomeação são múltiplas. Podemos afirmar, contudo, que ele não se identifica a esse significante, e, pela psicanálise, sabemos que "uma toxicomania não pode ser definida somente pela frequência e tipo de droga que o sujeito usa, mas sim pelo lugar que ela ocupa na subjetividade do paciente" (Nogueira, 2006, p. 148). Na vida desse sujeito, o uso da droga não se destaca por ser excessivo ou desregrado, estando muito mais próximo de ser o que permite, ao contrário, tanto certo distanciamento dos excessos do gozo invasivo do Outro sexo quanto uma aproximação identificatória ao modo de gozo do pai.

Independentemente do caráter atribuído a esse objeto, contudo, não podemos perder de vista que a chegada de Lucas à análise é marcada pelo significante droga e por suas consequências em diversos âmbitos, o que determina a importância da discussão sobre o tema no caso em questão. $\mathrm{O}$ uso da maconha leva-o à necessidade de responder juridicamente, imposição que se desdobra, neste caso, na possibilidade de responder também subjetivamente. Não se trata de uma equação direta, visto que é absolutamente possível cumprir uma medida sem implicar-se subjetivamente nela (Barroso, 2007), mas, para Lucas, a implicação acontece. A abertura para a palavra permitida pelo encontro com um analista possibilita que um discurso seja construído e que, a partir dele, possamos compreender o uso que Lucas faz da droga.

Para esse sujeito, tal objeto parece ser a resposta encontrada para aliviar a agitação do corpo: em lugar das mulheres que o "enlouquecem", a maconha "desliga-o". Não por acaso, seu uso é feito apenas entre colegas do sexo masculino, sem por em questão a diferença sexual e evidenciando apenas a igualdade dos "chegados". Também é a relação especular, em sua vertente de rivalidade, que aparece com o ex-namorado da ex-namorada - com ele, compartilha as mesmas escolhas de objeto: aquela mulher e a droga. No que podemos entender como o primeiro momento de sua experiência analítica, portanto, o Outro a que Lucas responde surge pela via da figura materna, imaginária, caprichosa, exigente e invasiva. Por esse motivo, não consegue sair da lógica do "perder ou ganhar". Quando perde, "perde tudo", impossibilitado de qualquer elaboração simbólica da perda.

A mãe que "se mata para não deixar nada faltar" tem sua divisão obturada. Situar-se toda como mãe, sabemos, é uma das saídas possíveis à mulher para não ter que se haver com sua condição nãotoda. A vertente materna escamoteia a castração, apresentando-se do lado do masculino da sexuação, do lado do Todo. A mãe de Lucas "fala muito", "irrita muito", "cobra muito". Sua demanda recai como imperativo e faz com que o sujeito se veja cada vez mais distante do ideal. Não sabe o que é possível ser além do que supõe ser o que a mãe espera que ele seja: "não sou como ela queria que eu fosse".

Os efeitos da análise de Lucas, contudo, são colhidos a partir de uma aposta de que haveria, para esse sujeito, um recurso simbólico: o significante paterno teria feito sua inscrição e poderia, assim, ser resgatado. Há um pai que incidiu e permitiu apostar em um sujeito do inconsciente embora, sobre isso, Lucas tenha chegado decidido a nada saber.

A proposta em que nos apoiamos é a de que o encontro com um analista pode ter como função restaurar a barra estabelecida pelo significante fálico. Como direção do tratamento, seria possível operar com os fragmentos do pai, com seus restos, de forma a promover, com eles, o reencontro de Lucas com a castração, que alivia o peso da demanda pulsional sobre esse sujeito colocado na condição de objeto 
de gozo. Cunha e Carneiro (2009) enfatizam a questão da fixação pulsional que geralmente acompanha a adição ao objeto droga, marcando a tentativa do ser falante de um retorno ao autoerotismo, que falha na medida em que há um acesso ao significante fálico.

No que chamamos de dois momentos da análise em questão, pareceu-nos que o que estava em jogo, de formas diferentes, era resgatar o pai e sua palavra, fazer com que a falta-a-ser aparecesse por debaixo da presença maciça do Outro. $\mathrm{O}$ amor, que se atrela à transferência, é a trilha possível nesse trabalho. Lucas constata que a escolha por uma mulher como objeto acalma-o, em oposição à agitação gerada pela série "das mulheres", no plural, com um gozo impossível de ser manejado.

Na neurose, o recurso à droga promove uma ruptura com o gozo fálico, mas sem que haja forclusão do significante paterno. Há, de partida, a recusa a saber sobre o inconsciente e a se haver com a impossibilidade da relação sexual, "[...] de modo que se torna dificil a invenção de um semblante que o proteja da compulsão a se drogar e do real que daí advém. Isso caracteriza a monotonia do gozo apresentada por esses sujeitos" (Reis, 2011, p. 6). Tal posição diferenciase radicalmente do uso da droga na psicose, em que a não-inscrição do significante fálico tem como efeito uma escassez de recursos simbólicos para lidar com o real que invade o ser. O objeto-droga surge, para o psicótico, como possibilidade de tratamento do real, permitindo, inclusive, uma estabilização pelo efeito trazido pelo uso e/ou pela identificação ao significante "toxicômano".

Apesar de, juridicamente, ser um autor de ato infracional, do ponto de vista subjetivo, Lucas não consegue transgredir sua condição neurótica de modo bem-sucedido - continua obedecendo ao jogo fálico, ainda que tente se livrar de seus efeitos. Há um furo em sua estratégia. Diferentemente do cínico, que não crê em nada, sua estrutura impede-o da esperteza de se livrar de vez da impossibilidade da relação sexual, fazendo com que "rode" em várias situações em que um verdadeiro desligamento do Outro poderia salvá-lo.

Lembramo-nos, aqui, da advertência de Lacan (19731974/2009): "les non du pere errent", tradicionalmente traduzido por "os não-tolos erram". O título faz homofonia com a expressão em francês les Noms du Père errent, ou, traduzindo livremente, "os Nomes do Pai erram/são errantes". A brincadeira linguística enfatiza o fato de a crença no simbólico, no Nome-do-Pai como ponto de basta, conduzir ao equívoco da busca incessante de sentido, que faz com que o real reste desconhecido. Em nosso caso clínico, podemos perceber que Lucas vacila, o que faz com que, ao menos na concepção lacaniana, não seja bobo o suficiente para crer de forma genuína na possibilidade de transgressão à limitação imposta pelo falo. Busca não saber, mas sabe algo sobre o pai e sua Lei. A posição subjetiva a ser assumida por ele em sua análise oscila entre não crer na droga, mas fazer uso dela por não querer saber ou crer no pai e, assim, poder prescindir dos objetos de usufruto direto para entrar ativamente no jogo da castração e ter que se haver com a angústia daí advinda.

Longe de resumir toda a questão de Lucas, sua proximidade com a droga merece ser abordada como paradigma de uma série de sintomas de nosso tempo. Por outro lado, acreditamos que o sujeito dividido pode surgir como possibilidade de tratamento desse modo de vida que eclipsa qualquer questionamento e qualquer endereçamento.

\section{Referências}

Barroso, A. F. (2007). Sobre como assistir à liberdade: psicanálise e responsabilização subjetiva na modernidade líquida (Unpublished master'sthesis) Pontifícia Universidade Católica de Minas Gerais. Belo Horizonte, MG.

Blanco, M. F. (2007). Cidadão-sintoma. Latusa Digital, 29(4). Retrieved from http://www.latusa.com.br/pdf_latusa digital_29_a1.pdf

Brousse, M-H. (2007). Em direção a uma nova clínica psicanalítica. Latusa digital, 30(4). Retrieved from http://www.latusa.com. br/pdf_latusa_digital_30_a1.pdf

Cunha; T. $\bar{C}$. M. C.; Carneiro, H. F. (2009, agosto). Drogadição, amor e poder: uma proposta de intervenção. In Anais do Congreso Internacional de Investigación en Psicoanálisis, Derecho y Ciencias Sociales, 2, Argentina. Retrieved from https://sites.google.com/a/fundpsicsigmundfreud.org/trabajos2do-congreso-de-investigacion/home

Lei n. 8.069 (1990). Dispõe sobre o Estatuto da criança e do adolescente. Brasília: Editora do Ministério da Saúde.

Figueiredo, A. C. (2004). A construção do caso clínico: uma contribuição da psicanálise à psicopatologia e à saúde mental. Revista Latinoamericana de Psicopatologia Fundamental, 1(7), 75-86.

Freud, S. (1996). Recomendações aos médicos que exercem a psicanálise. In S. Freud, Edição standard brasileira das obras psicológicas completas de Sigmund Freud (Vol. XII, p. 144153) (J. Salomão, Trans.). Rio de Janeiro: Imago. (Trabalho original publicado em 1912)

Lacan, J. (2009). Les non dupeerrant. Seminário inédito. Publicação interna da Escola Brasileira de Psicanálise do Recife. (Trabalho original publicado em 1973-1974)

Lacan, J. (1977). Abertura da seção clínica. Ornicar? 9, 7-14.

Lacan, J. (1992). O seminário, livro 17: o avesso da psicanálise. Rio de Janeiro: Jorge Zahar. (Trabalho original publicado em 1969-1970)

Lacan, J. (1995). O seminário, livro 20: mais, ainda. Rio de Janeiro: Jorge Zahar (Trabalho original publicado em 1972-1973)

Lacan, J (2003). Radiofonia. In Lacan, J. Outros escritos (p. 403447). Rio de Janeiro: Jorge Zahar. (Trabalho original publicado em 1970)

Lacan, J. (2003). Discurso de Roma. In J. Lacan, Outros Escritos (p. 509-543). Rio de Janeiro: Jorge Zahar (Trabalho original publicado em 1974)

Leite, M. P. S. (2001, outubro). Toxicomanias e pós-modernidade: um sintoma social? In Anais do Encontro latino-americano dos Estados Gerais da Psicanálise, 1, Rio de Janeiro. Retrieved from http://www.marciopeter.com.br/links2/artigos/txtCongrssos/ toxicomanias.html

Lopes, R. G. (2009). A psicanálise é o que reintroduz o Nome do Pai na consideração científica: o que isso significa nos primeiro e segundo ensinos de Lacan? Psicologia em Revista, 15(2), 17-35. 
Miller, J-A. (2003). O rouxinol de Lacan. Carta de São Paulo, São Paulo, 5(10), 18-32.

Nogueira, C. P. S. (2006). A família na toxicomania. In O. Cirino\& R. Medeiros (Eds.), Álcool e outras drogas: impasses, escolhas e saídas possiveis (pp. 147-156). Belo Horizonte: Autêntica.

Portillo, R. (2005). O declínio do ideal, a exigência de gozo. Latusa digital, 16(2).Retrieved from www.latusa.com.br/ pdf_latusa_digital_16_a1.pdf
Reis, J. (2011). O diagnóstico diferencial na clínica das toxicomanias. Opção Lacaniana online, nova série, 5(2). Retrieved from http://www.opcaolacaniana.com.br/pdf/numero_5/O_ diagn $\% \mathrm{C} 3 \% \mathrm{~B} 3$ stico_diferencial_na_cl $\% \mathrm{C} 3 \% \mathrm{ADnica}$ _das toxicomanias.pdf

Santiago, J. (2001). A droga do toxicômano. Rio de Janeiro: Jorge Zahar.

Vorcaro, A. (2004). Seria a toxicomania um sintoma social? Mental [online], 3(2), 61-73.Retrieved from http://pepsic.bvsalud. org/scielo.php?pid=S1679-44272004000200006\&script $=$ sci_ arttex 